\title{
Article
}

\section{The Ecosystem Services Value Change and Its Driving Forces Responding to Spatio-Temporal Process of Landscape Pattern in the Co-Urbanized Area}

\author{
Xinyu Zhang ${ }^{1,+}{ }^{\oplus}$, Huawei $\mathrm{Li}^{1,+}{ }^{1}$, Hua Xia ${ }^{1}{ }^{\mathbb{D}}$, Guohang Tian ${ }^{1}$, Yuxing Yin ${ }^{1}$, Yakai Lei ${ }^{1, *}$ and Gunwoo Kim ${ }^{2}$ \\ 1 College of Landscape Architecture and Art, Henan Agricultural University, Zhengzhou 450002, China; \\ 15824890524@163.com (X.Z.); lihuawei2010@hotmail.com (H.L.); xiahua19970224@163.com (H.X.); \\ tgh@henau.edu.cn (G.T.); yuxingyin@henau.edu.cn (Y.Y.) \\ 2 Graduate School of Urban Studies, Hanyang University, 222 Wangsimni-ro, Seongdong-gu, Seoul 04763, Korea; \\ gwkim1@hanyang.ac.kr \\ * Correspondence: lykfjyl@henau.edu.cn; Tel.: +86-182-0360-8869 \\ + These authors contributed to this work equally and should be regarded as co-first authors.
}

\section{check for}

updates

Citation: Zhang, X.; Li, H.; Xia, H.; Tian, G.; Yin, Y.; Lei, Y.; Kim, G. The Ecosystem Services Value Change and Its Driving Forces Responding to Spatio-Temporal Process of

Landscape Pattern in the Co-Urbanized Area. Land 2021, 10 , 1043. https://doi.org/10.3390/ land10101043

Academic Editor:

Thomas Panagopoulos

Received: 31 August 2021

Accepted: 30 September 2021

Published: 3 October 2021

Publisher's Note: MDPI stays neutral with regard to jurisdictional claims in published maps and institutional affiliations.

Copyright: (c) 2021 by the authors Licensee MDPI, Basel, Switzerland. This article is an open access article distributed under the terms and conditions of the Creative Commons Attribution (CC BY) license (https:/ / creativecommons.org/licenses/by/ $4.0 /)$.

\begin{abstract}
The development of urbanization is still expanding on the earth, and the rapid expansion of cities has changed the regional landscape pattern and significantly affected the value of regional ecosystem services in developing countries such as China. Zhongmu County, as the core area of Zhengzhou-Kaifeng integration, studying the temporal and spatial transformations of its landscape pattern and ecosystem service value (ESV) is of great significance to the region's sustainable development. Based on remote sensing images and socioeconomic data, this study aims to explore the landscape pattern of Zhongmu County from 2005 to 2018 and its impact on ESV. Research methods include an ESV equivalent factor method, landscape pattern index, spatial autocorrelation, and other methods. The results showed that: (1) During the study period, the patch density and shape complexity, landscape diversity, and fragmentation of the overall landscape in the study area continued to increase while landscape connectivity decreased. (2) The total amount of ESV increased by 10.05 million USD; ESV had certain differences in spatial distribution: high-value clusters were mainly located at the boundary of the Yellow River in the north, while low-value clusters had a significant eastward expansion trend. (3) ESV increased significantly in areas where cultivated land was transferred to waters and forests, and ESV in areas where waters transferred to construction land and cultivated land was significantly reduced. (4) ESV had a significant positive spatial correlation with patch density, edge density, mean patch fractal dimension, mean patch size, and the landscape shape index, and a spatially negative correlation with the contagion index and cohesion index. The spatial and temporal changes in landscape patterns and ESV were all mainly driven by the regional development "Zhengzhou-Kaifeng integration" policy. Therefore, the ESV can be improved, and the ecological security of the urban integration area can be guaranteed through policy measures such as optimizing the layout of construction land and adjusting the uniform distribution of green areas by the land-use policy.
\end{abstract}

Keywords: ecosystem service value (ESV); Zhongmu County; landscape pattern; spatio-temporal changes; spatial relationship; "Zhengzhou-Kaifeng integration" policy

\section{Introduction}

Ecosystem services (ESs) refer to life support products and services that humans obtain directly or indirectly through the structure, process, and function of ecosystems [1-3]. The United Nations Millennium Ecosystem Assessment (MA) divides ES into four categories: support, regulation, supply, and cultural functions [4]. Ouyang et al. [5] found that ES forms the life support system on which human beings depend, such as the generation and maintenance of biodiversity, climate regulation, nutrient storage and cycling, soil renewal, 
environmental purification and degradation of harmful substances, and reduction in natural disasters. Therefore, ES is the foundation of human survival and development. At the same time, for humans and nature to coexist harmoniously, it is of great significance in the protection of environmental resources, the maintenance of regional ecological security, and the sustainable development of human society. Ecosystem service value (ESV) is an important indicator to quantify ES [6]. Evaluating ESV is a key way to measure the effectiveness of environmental protection [7] and conducive to an in-depth understanding of the functional status of the ecosystem and the relationship between man and land. It has important reference value for regional ecological compensation, ecological security pattern construction and ecological civilization construction [8-10].

The production of ES is derived from human needs, and only when ecological functions are related to human needs can they reflect a certain value. As the carrier of the ecological process, the relationship between landscape pattern and ESV is reflected in the interaction between landscape pattern and the ecological process [11]. Landscape pattern refers to the type, number, spatial distribution, and configuration of units comprising a landscape [12]. As the core content of landscape ecology, landscape pattern helps better reflect the changing process of ecosystems [13]. At the same time, it is also closely related to ESV: on the one hand, landscapes of different types and structures provide diverse ES and correspondingly form ESV of different types, quantities, and qualities [14]; on the other hand, the most direct manifestation of landscape pattern change is land-use change [15]. Land-use change can change the structure and function of the ecosystem, which affects its material cycle, energy flow, and product and service supply, and leads to corresponding changes in ESV in time and space [16].

In the 21st century, as urbanization continues to accelerate, the landscape pattern is changing significantly. In order to guarantee the continuous supply and steady improvement of ES, research on the relationship between landscape patterns and ESV has attracted more and more attention globally. Grêt-Regamey et al. [17] found that landscape fragmentation is particularly critical for ESV provided by species-rich habitats; Soy-Massoni et al. [18] combined ESV to assess the importance and multiple benefits of the Mediterranean agricultural landscape; Cen et al. [19] used the correlation analysis, gray correlation and the redundancy analysis to quantitatively prove that the increase in the richness, fragmentation and dispersion of the landscape on the south bank of Hangzhou Bay was conducive to improving the overall ESV; Guo et al. [20] used the landscape pattern index to find that the ecological environment index and landscape zoning index had a positive impact on the ESV of Kunshan City, while the largest patch index, contagion index, similar proximity ratio, patch cohesion index and aggregation the index had a negative impact on ESV. In general, the current related exploration has evolved from analyzing ESV in combination with landscape types to quantitatively assessing the relationship between the two using various indicators and methods, and the research scope has also developed from larger scales such as national, provincial, and municipal scales to refined scales such as regional geographic space [21]. However, there are shortcomings: (1) There are relatively few studies on the landscape pattern and ESV in smaller administrative units, such as the most basic administrative unit in China-a county level; (2) there is less analysis on the spatial correlation characteristics of landscape pattern and ESV; (3) there are relatively few practical strategies for landscape pattern optimization based on ESV enhancement. Therefore, it is necessary to strengthen further and deepen the research on related issues.

The urbanization rate in China reached $60.6 \%$ in 2019 [22]. In recent years, the "integration of urban agglomerations" that emphasizes the integration and development of cities has become an important direction for urbanization development [23]. For instance, Zhengzhou-Kaifeng integration as a breakthrough in the construction of the Central Plains urban agglomeration, aims to strengthen the co-construction and sharing of infrastructure between Zhengzhou City and Kaifeng City, and promote the deep integration of the two cities and lead the construction of the Zhengzhou metropolitan area [24,25]. As the core area and strategic fulcrum of Zhengzhou-Kaifeng integration, Zhongmu County rapidly 
increased its urbanization development speed. From 2005 to 2018, Zhengkai Avenue and Zhengkai Intercity Railway in Zhongmu County were completed and opened to traffic. A comprehensive transportation system coordinated with the Zhengzhou-Kaifeng integration strategy was initially established. At the same time, the construction land for industrial parks and residential communities is increasing, and the urban development pattern of "three axes, three districts, and multiple clusters" was initially formed. It can be seen that the landscape pattern of Zhongmu County has undergone rapid and drastic changes [26]. At the same time, ES, which is closely related to it, will inevitably be affected. In order to prevent the ES of Zhongmu County from being negatively affected by urbanization, the stable supply and gradual increase in ESV must be ensured, and at the same time the balanced development of ecological environmental protection and the construction of Zhengzhou-Kaifeng integration must be realized.

This study was based on the remote sensing images and socioeconomic data of Zhongmu County from 2005 to 2018, and used multiple methods such as the ecosystem service value equivalent factor method, landscape pattern index, land-use transfer matrix, cold and hot spots analysis and spatial autocorrelation to analyze the spatio-temporal changes in Zhongmu County's landscape pattern and the ESV in the Zhengzhou-Kaifeng integration. The equivalent factor method was used to evaluate the value of the ecosystem in Zhongmu County. The landscape pattern index was used to express the dynamic changes in different landscape pattern characteristics in Zhongmu County, such as landscape composition, fragmentation, and connectivity. The land-use transfer matrix was used to reflect the temporal and spatial changes in the landscape pattern in Zhongmu County from 2005 to 2018. The cold and hot spots analysis was used to explore whether there are statistically significant hot and cold spot clusters in the ESV variation in Zhongmu County, and determine the location of the hot spot clusters and cold spot clusters in Zhongmu County. The spatial autocorrelation analysis method was used to reflect the spatial distribution of ESV itself and the characteristics of landscape patterns in Zhongmu County. The objectives of this study were: (1) in-depth exploration of the dynamic response between landscape pattern and ESV; (2) to explore how to optimize the landscape pattern of urban integration areas; (3) to discuss the dynamics of driving forces and their impact on the development and planning of urban integration areas.

\section{Materials and Methods}

\subsection{Study Area}

Zhongmu County is a county under the jurisdiction of Zhengzhou City, the capital of Henan Province $\left(34^{\circ} 26^{\prime}-34^{\circ} 56^{\prime} \mathrm{N}, 113^{\circ} 46^{\prime}-114^{\circ} 12^{\prime}\right.$ E) [27]. Located in the hinterland of the Central Plains, on the shore of the Yellow River. It is a warm temperate continental monsoon climate with abundant water resources and more than 40 large and small rivers. Zhongmu County is adjacent to the central urban area of Zhengzhou City in the west and the Western New District of Kaifeng City in the east. It is the core area and strategic fulcrum of the Zhengzhou-Kaifeng Integration. At the same time, as the main battlefield of Zhengzhou City's eastward expansion, it is located in the "three districts" superimposed development area of the Central Plains urban agglomeration, Zhengzhou metropolitan area, and the Zhengzhou Airport Economic Comprehensive Experimental Zone. The Zhongmu County Urban-Rural Master Plan (2015-2030) indicates that the administrative area of Zhongmu County will deduct the Baisha group that is classified into the Zhengdong New District, the Jiulong group that is classified into the Economic and Technological Development Zone, and the area outside the Airport Economic Comprehensive Experimental Zone, with a planned area of about $934 \mathrm{~km}^{2}$ [26]. Since the above areas in Zhongmu County were not classified into other regions in 2005 and 2010, their development had an important relationship with and impacts on the landscape pattern and ecological environment of Zhongmu County. As well as to facilitate the comparison of ESV spatio-temporal characteristics between different years, the research chose to conduct 
the analysis based on the extent of Zhongmu County in 2005, whose location and satellite images are shown in Figure 1.

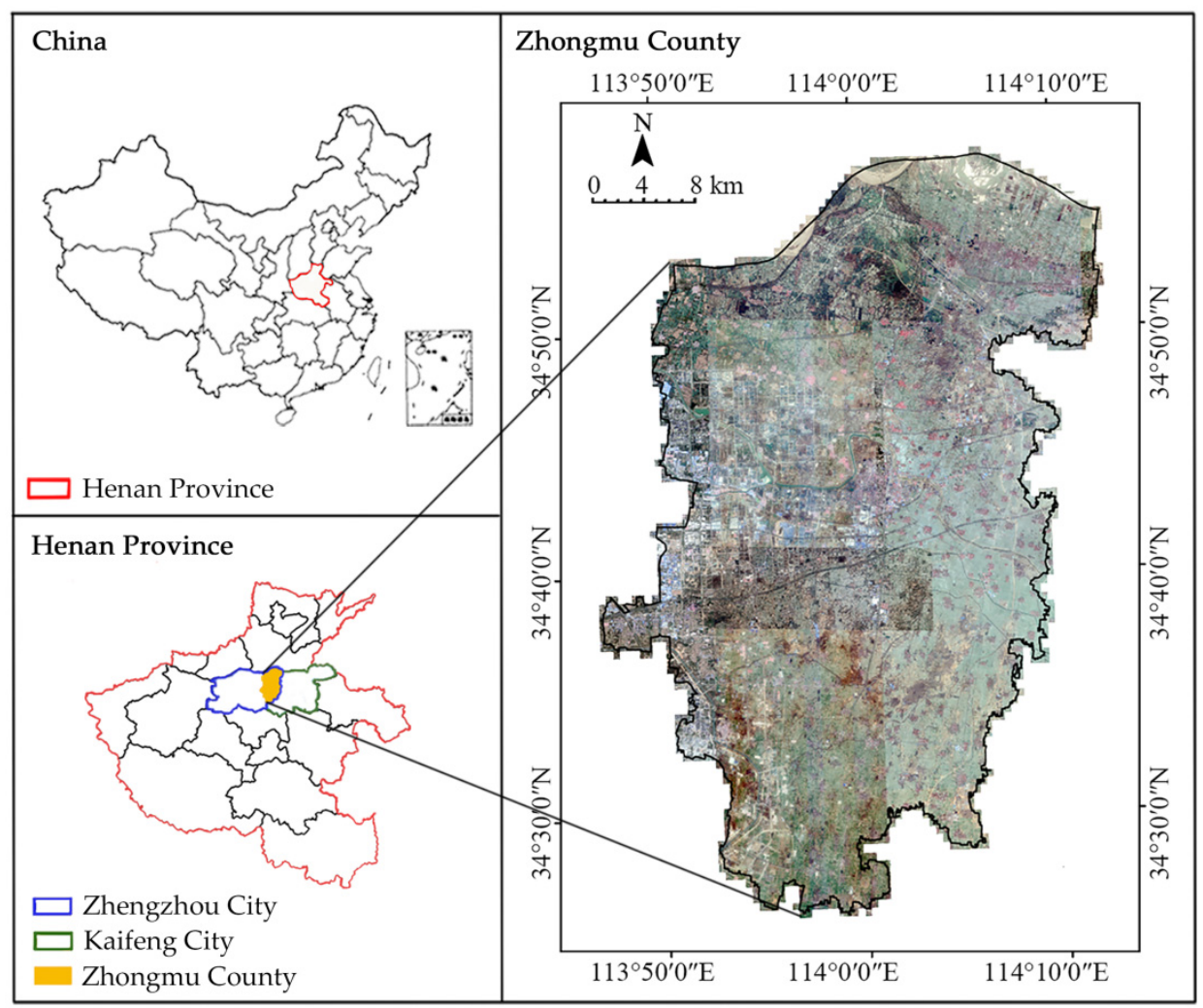

Figure 1. Location and satellite image of Zhongmu County.

\subsection{Data Sources}

\subsubsection{Geospatial Data}

The landscape classification data and administrative division data of the three phases of Zhongmu County in 2005, 2010 and 2018 are all sourced from the Resource and Environmental Science Data Center of the Chinese Academy of Sciences (http:/ / www.resde.cn, accessed on 24 December 2020). The landscape classification data is a raster map (resolution $30 \mathrm{~m}$ ) generated by manual visual interpretation of remote sensing images, and the interpretation accuracy is more than $90 \%$. The administrative division data of Zhongmu County was combined and the clipping tool of the ArcGIS 10.2 software was used to clip the $30 \mathrm{~m}$ raster map of China's land-use remote sensing monitoring, from which the landscape classification map of Zhongmu County can be obtained. The classification is based on the "China Land Use/Land Cover Remote Sensing Monitoring data classification system", and the specific classification description is shown in Table A1. Using ArcGIS 10.2, the study area was divided into $1 \mathrm{~km} \times 1 \mathrm{~km}$ fishing nets, and a total of 1511 grids were formed. Calculating the ESV and landscape pattern index in the grid separately can further realize the in-depth exploration of the spatial dynamics of ESV and landscape pattern characteristics and the spatial coupling relationship between the two at a smaller unit scale.

\subsubsection{Economic Data}

The crop and grain output in Zhongmu County from 2005 to 2018 are from the Henan Statistical Yearbook and Zhongmu County National Economic and Social Development Statistical Bulletin. Comprehensively, the average grain output from 2005 to 2018 is $5880.14 \mathrm{~kg} / \mathrm{ha}$; Grain prices come from the China Agricultural Product Price Survey Yearbook and the Grain and Material Reserve Bureau of Henan Province (http: //1swz.henan.gov.cn, accessed on 24 December 2020). To reduce the impact of the price 
fluctuations of different types of crops on the total value, the study used the main food types in Zhongmu County in 2018: wheat, corn, and rice as basic data. For the time being, the impact of climate on food prices was considered.

\subsection{Methods}

\subsubsection{Landscape Pattern Index}

In order to describe the dynamic changes in different landscape pattern features such as landscape composition, fragmentation, and connectivity in Zhongmu County from 2005 to 2018, and reduce the one-sidedness and limitations of a single index, this study selected ten representative landscape pattern indexes. The descriptions of the indexes are shown in Table A2. The comprehensive analysis of the ten indexes can more comprehensively reflect the characteristics of the landscape pattern of Zhongmu County from 2005 to 2018, and conduct landscape dynamic research. The index calculation was performed in the Fragstats 4.2.1 software.

\subsubsection{Land-Use Transfer Matrix}

The land-use transfer matrix can quantitatively describe the mutual transfer of landscape types in the initial and final stages of Zhongmu County, and reflect the transfer direction and nature of various landscapes, and then reveal the structural characteristics of multiple landscapes before and after the transfer. It can also effectively reflect the spatio-temporal changes in the landscape pattern in Zhongmu County during a certain period $[28,29]$. The formula is:

$$
S_{i j}=\left[\begin{array}{cccc}
S_{11} & S_{12} & \cdots & S_{1 n} \\
S_{21} & S_{22} & \cdots & S_{2 n} \\
\vdots & \vdots & \vdots & \vdots \\
S_{n 1} & S_{n 2} & \cdots & S_{n n}
\end{array}\right]
$$

where $S$ is the area of various landscapes, $n$ is the number of landscape types, and $i$ and $j$ are the landscape types at the beginning and end of the study, respectively.

\subsubsection{Ecosystem Service Value Assessment}

The equivalence factor method is the main method to evaluate the value of the ecosystem. Scholars have widely adopted it to quantify ESV because it is easy to use, requires less data, and has highly comparable results $[30,31]$. The method can evaluate the value of the ecosystem in Zhongmu County. The method was first proposed by Costanza and modified by Xie Gaodi and other scholars to derive the equivalent factor of the terrestrial ecosystem service value in China (Table A3), which is defined as the economic value of one identical factor equal to $1 / 7$ of the market value of the average grain yield in the study area in the current year [32]. The formula is as follows:

$$
\begin{aligned}
& E_{1}=Q_{1} \times F_{1} / 7 \\
& E_{x}=a_{x} / a_{1} \times E_{1}
\end{aligned}
$$

where $Q_{1}$ is the average grain output, $F_{1}$ is the average grain price. $E_{x}$ is the ESV per unit area of landscape type $x, a_{1}$ is the value equivalent of dry land, and $a_{x}$ is the value equivalent of other landscape types. Since this method does not involve construction land, this study does not consider the ESV of construction land [15]. In addition, according to Formulas (4) and (5), the ESV of different landscape types and different ES functions can be obtained, and the formulas are as follows:

$$
E S V=\sum_{k=1}^{n} A_{k} \times V C_{k} .
$$




$$
E S V_{f}=\sum_{k=1}^{n}\left(A_{k} \times V C_{f k}\right)
$$

where $A_{k}$ and $V C_{k}$ represent the area and ESV coefficient of landscape type $k$, respectively, $E S V_{f}$ represents the value of the fth ecosystem service function, and $V C_{f k}$ represents the ESV coefficient of the fth service function of landscape type $k$ [33].

\subsubsection{Analysis of Cold and Hot Spots of ESV}

The cold and hot spot analysis was used to explore whether there are statistically significant hot and cold spot clusters in the ESV variation in Zhongmu County, and determine the hot spot clusters' location [34]. The hot spot indicates that the ESV of Zhongmu County increased significantly, and the increase is much higher than that of the surrounding area; the cold spot indicates that the ESV of Zhongmu County dropped significantly, and the decrease is far more than that of the surrounding area. The cold and hot spot analysis is based on the Getis-Ord $G i^{*}$ index, the formula is:

$$
G_{i}^{*}=\frac{\sum_{j=1}^{n} W_{i j} X_{j}-\bar{X} \sum_{j}^{n} W_{i j}}{\sqrt[s]{\frac{\left[n \sum_{j=1}^{n} W_{i j}{ }^{2}-\left(\sum_{j=1}^{n} W_{i j}\right)^{2}\right]}{(n-1)}}}
$$

where $X_{j}$ is the attribute value of spatial unit $j ; W_{i j}$ represents the spatial weight between spatial units $i$ and $j$ (adjacent is 1, non-adjacent is 0 ); $n$ is the number of spatial units; $\bar{X}$ is the mean value.

\subsubsection{Spatial Autocorrelation of ESV}

The spatial autocorrelation analysis method can reflect the spatial distribution of ESV itself and the characteristics of landscape patterns in Zhongmu County. Spatial autocorrelation analysis measures whether the distribution of elements is spatially related to neighboring elements [35], including global spatial autocorrelation and local spatial autocorrelation. Global autocorrelation is used to describe the degree and significance of the spatial correlation between variables in a region. The local spatial autocorrelation is usually analyzed by Moran's I scatter plot and local indicators of spatial association (LISA). Moran's I scatter diagram can reflect the correlation between spatial unit elements and neighboring elements. At the same time, LISA decomposes global Moran's I into each spatial unit and forms a LISA clustering map, which can show the specific location of the spatial aggregation or differentiation of ESV and landscape pattern [36,37], the correlation mode of Moran's I scatter plot and LISA cluster plot is shown in Table 1. The following are the calculation formulas for the global Moran's I index and the local Moran's I index:

$$
\begin{gathered}
I=\sum_{i=1}^{n} \sum_{j=1}^{n} w_{i j}\left(x_{i}-\bar{x}\right)\left(x_{j}-\bar{x}\right) / S^{2} \sum_{i=1}^{n} \sum_{j=1}^{n} w_{i j} \\
I_{i}=\frac{\left(x_{i}-\bar{x}\right)}{S^{2}} \sum_{j} w_{i j}\left(x_{j}-\bar{x}\right) \\
S^{2}=\frac{1}{n} \sum_{j}\left(x_{i}-\bar{x}\right)^{2}
\end{gathered}
$$

where $I$ is global Moran's I; $n$ is the total number of spatial units; $\mathrm{x}$ is the element value; $W_{i j}$ is the spatial weight, and $S^{2}$ is the variance. This study builds $W_{i j}$ based on the queen adjacency criterion commonly used by the GeoDa software. When the spatial units are adjacent, the value of $W_{i j}$ is 1 , otherwise, it is 0 . The value of $I$ is $(-1,1)$. The closer $I$ is to 1 , the stronger the positive spatial correlation of the elements. The more concentrated the distribution, the closer to -1 , the stronger the negative spatial correlation and the 
greater the distribution difference; equal to 0 it shows no spatial autocorrelation, and the distribution is random $[37,38]$.

Table 1. Association pattern of Moran's I scatter plot and LISA clustering map.

\begin{tabular}{|c|c|c|c|}
\hline Scatter Image Limit & LISA Gathering & Spatial Correlation & Description \\
\hline First quadrant & High-High Cluster & Positive spatial correlation & $\begin{array}{l}\text { The element values of the spatial } \\
\text { unit and its forest are high, and } \\
\text { the spatial difference is small. }\end{array}$ \\
\hline Second quadrant & Low-High Outlier & Spatial negative correlation & $\begin{array}{l}\text { The element value of the spatial } \\
\text { unit is low, the element value of } \\
\text { its neighborhood is high, and the } \\
\text { spatial difference is large. }\end{array}$ \\
\hline Third quadrant & Low-Low Cluster & Positive spatial correlation & $\begin{array}{l}\text { The feature value of the spatial } \\
\text { unit and its neighborhood is low, } \\
\text { and the spatial difference is small. }\end{array}$ \\
\hline Fourth quadrant & High-Low Outlier & Spatial negative correlation & $\begin{array}{l}\text { The higher the element value of a } \\
\text { spatial unit, the lower the element } \\
\text { value of its neighbors, and the } \\
\text { greater the spatial difference. }\end{array}$ \\
\hline
\end{tabular}

\section{Results}

\subsection{Dynamic Analysis of Landscape Pattern}

\subsubsection{Dynamic Analysis of the Overall Landscape}

The landscape composition of Zhongmu County was dominated by dry land. Large paddy fields were distributed from east to west in the north, urban land was mainly distributed in the central and western regions, and rural residential areas were widely scattered in the central and southern regions (Figure 2). From 2005 to 2018, the distribution of paddy fields in the northwest corner decreased significantly. The central part's urban and other construction lands increased significantly, and the scattered gardens in the south also reduced.

From 2005 to 2018, ED, SHAPE_MN, PD, LSI, and SHDI in Zhongmu County all showed an upward trend year by year (Table 2), and the values of CONTAG and COHESION showed a downward trend. It showed that the density of landscape edges in Zhongmu County increased during the study period. With the increase in patches per unit area, patch shapes became more and more complex, and landscape diversity increased. However, the degree of fragmentation of the landscape was also growing year by year, and the overall landscape connectivity was decreasing and the degree of patch dispersion was increasing year by year.

Table 2. Changes in landscape level pattern index.

\begin{tabular}{ccccccccc}
\hline Years & ED & FRAC_MN & SHAPE_MN & PD & COHESION & LSI & CONTAG & SHDI \\
\hline 2005 & 10.13 & 1.06 & 1.50 & 0.31 & 99.86 & 14.95 & 74.56 & 1.18 \\
2010 & 10.58 & 1.07 & 1.55 & 0.32 & 99.87 & 15.57 & 73.82 & 1.21 \\
2018 & 11.40 & 1.07 & 1.56 & 0.34 & 99.79 & 16.70 & 72.35 & 1.28 \\
\hline
\end{tabular}

\subsubsection{Analysis of Landscape Element Transfer}

Table 3 showed that dry land was the main source of increase in other landscape types. The reduction in dry land from 2005 to 2018 was $206.80 \mathrm{~km}^{2}$, which was the largest reduction among all landscape types, and the landscape type with the largest transfer area of dry land was rural residential land and the deduction was $73.80 \mathrm{~km}^{2}$. In addition, the size of urban land, rural residential land and other construction land transferred to woodland, gardens, high-coverage grassland, canals and reservoir pond did not exceed $1.15 \mathrm{~km}^{2}$, indicated that less construction land was transformed into ecological landscapes. 
The input source of the ecological landscape was relatively single, and the input was much lower than the output.

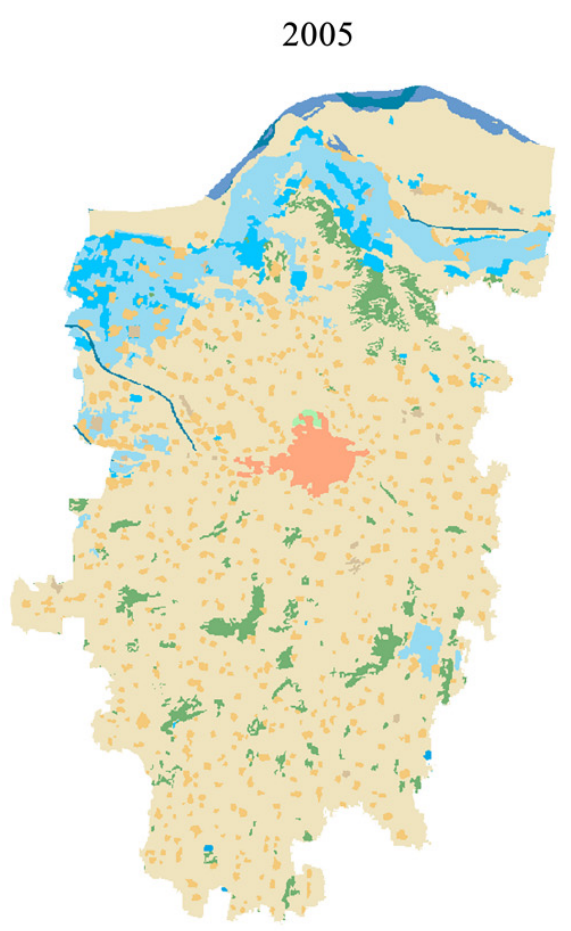

$\square$ Paddy field $\square$ Dry land $\square$ Woodland
$\square$ Canal
$\square$ Reservoir pond $\square$ Bottomland
2010
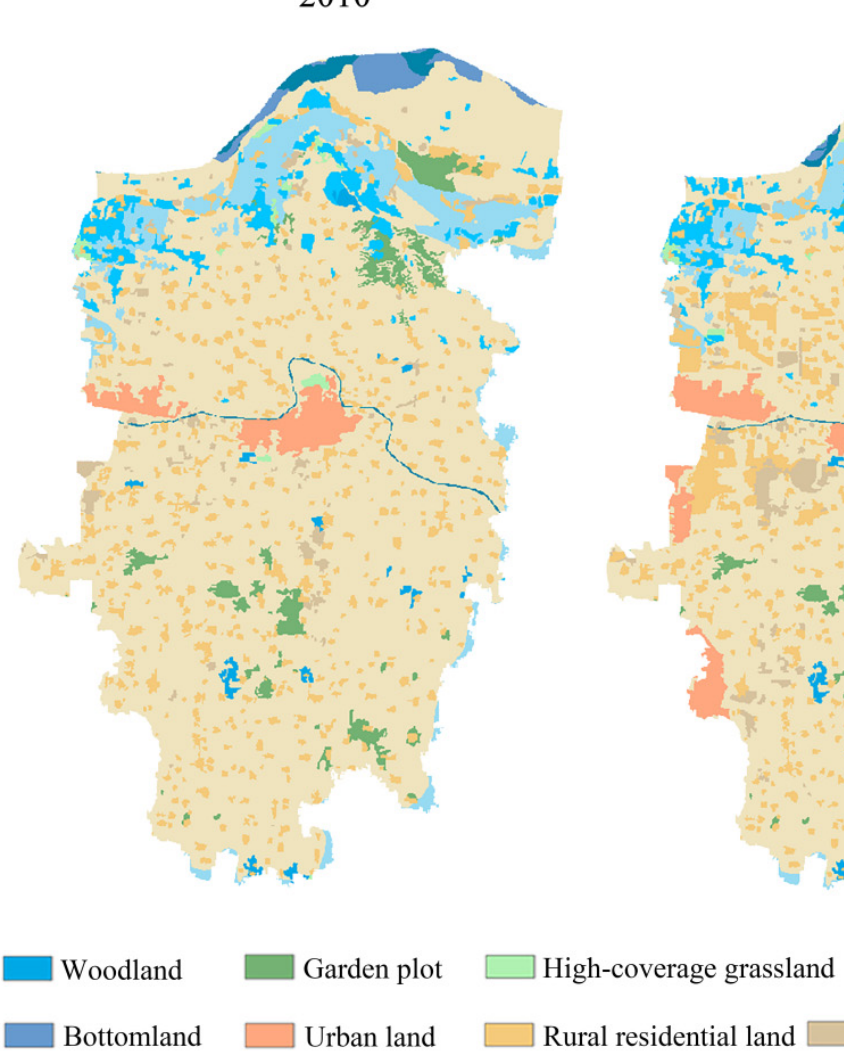

2018
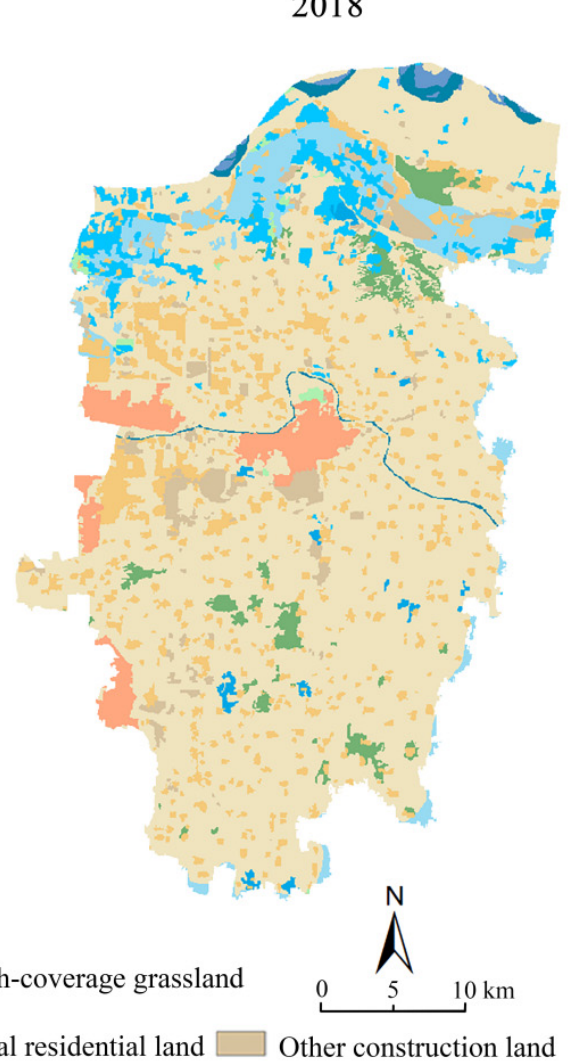

Figure 2. Landscape classification map of Zhongmu County.

\subsection{ESV Analysis}

\subsubsection{Temporal Changes in ESV}

From 2005 to 2018, the ESV of Zhongmu County showed a positive growth state. The total amount of ESV increased by 10.05 million USD (Table 4). The increase rate was $3.08 \%$. Among all types of landscape ESV, the ESV of dry land always remained the highest from 2005 to 2018, and the average contribution rate of dry land was as high as $37.46 \%$; while the average contribution rate of high-coverage grassland ESV was the smallest, $0.76 \%$; the ESV of dry land and paddy fields, and their contribution rate showed a declining trend; while the ESV contribution rate of reservoir ponds and canals was constantly increasing.

Among the individual service values in Zhongmu County, as shown in Table 5, the average contribution rate of adjustment services was the highest, accounting for $58.61 \%$ of the overall ESV. Among the 11 secondary ecosystem service functions, the ESV of hydrological regulation has always remained the largest, with an average contribution rate of $33.64 \%$ during the study period. The ESV of water resources supply always remained the smallest during the study period, with an average contribution rate of only $0.58 \%$. From the perspective of the rate of change, only the rate of change in hydrological regulation ESV from 2005 to 2018 was positive and showed a trend of first decreasing and then increasing; while the rate of change in the other four types of service functions were all negative, including soil conservation; the rate of reduction in gas regulation and food production was increasing. 
Table 3. Landscape area transfer matrix from 2005 to 2018 (Unit: $\mathrm{km}^{2}$ ).

\begin{tabular}{|c|c|c|c|c|c|c|c|c|c|c|c|c|}
\hline 2018 & 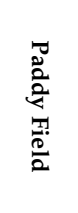 & 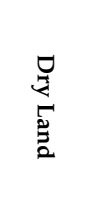 & 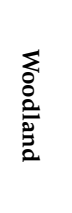 & $\begin{array}{l}0 \\
0 \\
0 \\
0 \\
0 \\
0 \\
0 \\
0\end{array}$ & 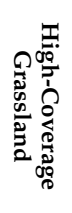 & 象 & $\begin{array}{l}\pi \\
0 \\
0 \\
0 \\
0 \\
0 \\
0 \\
0 \\
0 \\
0 \\
0\end{array}$ & 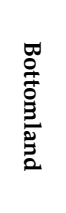 & 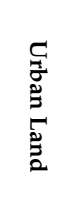 & 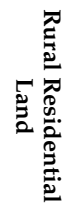 & 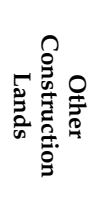 & 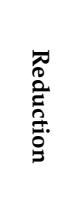 \\
\hline Paddy field & 44.55 & 42.06 & 0.00 & 0.02 & 1.05 & 0.02 & 13.51 & 0.00 & 4.53 & 7.44 & 6.57 & 75.20 \\
\hline Dry land & 25.10 & 785.48 & 6.13 & 18.60 & 1.78 & 8.75 & 13.57 & 2.14 & 24.16 & 73.80 & 32.77 & 206.80 \\
\hline Woodland & 0.30 & 0.33 & 0.00 & 0.00 & 0.00 & 0.00 & 0.00 & 0.00 & 0.00 & 0.00 & 0.00 & 0.63 \\
\hline Garden plot & 0.60 & 30.14 & 2.33 & 19.27 & 0.21 & 0.08 & 2.39 & 0.00 & 0.90 & 2.53 & 1.72 & 40.89 \\
\hline $\begin{array}{l}\text { High-coverage } \\
\text { grassland }\end{array}$ & 0.00 & 0.21 & 0.00 & 0.00 & 0.79 & 0.00 & 0.00 & 0.00 & 0.02 & 0.00 & 0.07 & 0.30 \\
\hline Canal & 0.33 & 4.65 & 0.00 & 0.46 & 0.05 & 1.17 & 1.39 & 0.55 & 0.18 & 0.03 & 0.05 & 7.68 \\
\hline Reservoir pond & 3.51 & 4.44 & 0.01 & 0.25 & 0.90 & 0.00 & 26.86 & 0.00 & 0.00 & 2.50 & 4.50 & 16.11 \\
\hline Bottomland & 0.00 & 7.43 & 0.00 & 0.00 & 0.23 & 3.94 & 0.41 & 3.76 & 0.00 & 0.47 & 0.00 & 12.47 \\
\hline Urban land & 0.00 & 3.25 & 0.00 & 0.00 & 0.42 & 0.16 & 0.00 & 0.00 & 15.92 & 1.02 & 0.27 & 5.12 \\
\hline $\begin{array}{l}\text { Rural residential } \\
\text { land }\end{array}$ & 1.11 & 27.01 & 0.19 & 0.86 & 0.07 & 0.08 & 1.15 & 0.00 & 5.82 & 71.38 & 2.41 & 38.69 \\
\hline $\begin{array}{l}\text { Other construction } \\
\text { land }\end{array}$ & 0.28 & 3.05 & 0.00 & 0.34 & 0.00 & 0.02 & 0.09 & 0.00 & 0.85 & 1.21 & 0.61 & 5.83 \\
\hline Increments & 31.22 & 122.56 & 8.67 & 20.52 & 4.69 & 13.04 & 32.51 & 2.68 & 36.47 & 89.02 & 48.35 & - \\
\hline
\end{tabular}

\subsubsection{Spatial Changes in ESV}

Figure 3 and Table 6 showed that the spatial distribution of total ESV in Zhongmu County from 2005 to 2018 was dominated by low-value areas. The average ESV of $80.01 \%$ of the spatial units was less than USD 0.24 million. ESV high-value areas were distributed in the Yellow River in the north, and the average proportion of spatial units was only $0.53 \%$; ESV higher-value areas were mainly distributed in the Yellow River, Yanming Lake, northwest paddy fields and water areas in the north, the average ratio was only $2.36 \%$; there were mainly ESV low-value areas in the middle and southern part of Zhongmu County. 
Table 4. Changes in ESV of different landscape types in Zhongmu County from 2005 to 2018.

\begin{tabular}{|c|c|c|c|c|c|c|}
\hline & 2005 & 2010 & 2018 & & 2005-2018 & \\
\hline 芯 & 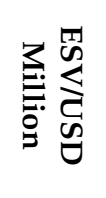 & 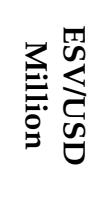 & 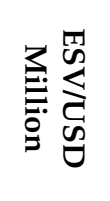 & 当党 & 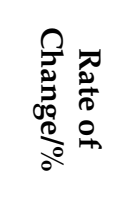 & 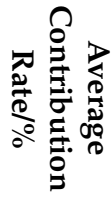 \\
\hline Dry land & 129.06 & 128.18 & 118.10 & -10.96 & -8.49 & 37.46 \\
\hline Paddy field & 15.11 & 10.17 & 9.56 & -5.55 & -36.73 & 3.49 \\
\hline Woodland & 0.47 & 6.85 & 6.49 & 6.01 & 1267.46 & 1.36 \\
\hline Garden plot & 45.06 & 30.07 & 29.80 & -15.26 & -33.86 & 10.51 \\
\hline $\begin{array}{l}\text { High-coverage } \\
\text { grassland }\end{array}$ & 0.69 & 3.52 & 3.50 & 2.81 & 404.56 & 0.76 \\
\hline Reservoir pond & 72.49 & 76.93 & 100.17 & 27.68 & 38.18 & 24.88 \\
\hline Bottomland & 27.39 & 30.80 & 10.87 & -16.52 & -60.32 & 6.90 \\
\hline Canal & 36.04 & 53.38 & 57.87 & 21.82 & 60.55 & 14.65 \\
\hline Total & 326.32 & 339.90 & 336.36 & 10.05 & 3.08 & 100.00 \\
\hline
\end{tabular}

Table 5. Changes in ESV of different ES in Zhongmu County from 2005 to 2018.

\begin{tabular}{|c|c|c|c|c|c|}
\hline \multirow{2}{*}{ Level 1 Function } & \multirow{2}{*}{ Secondary Function } & \multicolumn{3}{|c|}{ Rate of Change/\% } & \multirow{2}{*}{$\begin{array}{c}\text { Average Contribution } \\
\text { Rate } / \%\end{array}$} \\
\hline & & 2005-2010 & $2010-2018$ & 2005-2018 & \\
\hline \multirow{3}{*}{ Provision of services } & Food production & -5.18 & -7.03 & -11.85 & 9.74 \\
\hline & Raw material production & -1.78 & -6.49 & -8.16 & 4.54 \\
\hline & Water supply & -323.12 & 24.53 & -377.84 & 0.58 \\
\hline \multirow{4}{*}{ Regulation service } & Gas regulation & -5.10 & -5.43 & -10.25 & 9.79 \\
\hline & Climate regulation & -5.14 & -2.62 & -7.62 & 10.16 \\
\hline & Purify the environment & 3.52 & 0.55 & 4.09 & 5.02 \\
\hline & Hydrological regulation & 13.21 & 3.45 & 17.11 & 33.64 \\
\hline \multirow{3}{*}{ Support service } & Soil conservation & -1.11 & -5.78 & -6.82 & 12.71 \\
\hline & Maintain nutrient circulation & -5.31 & -6.32 & -11.29 & 1.53 \\
\hline & Biodiversity & 2.26 & 0.60 & 2.87 & 7.93 \\
\hline \multirow[t]{2}{*}{ Cultural service } & Aesthetic landscape & 3.95 & 1.16 & 5.16 & 4.37 \\
\hline & Total & 4.16 & -1.04 & 3.08 & 100.00 \\
\hline
\end{tabular}

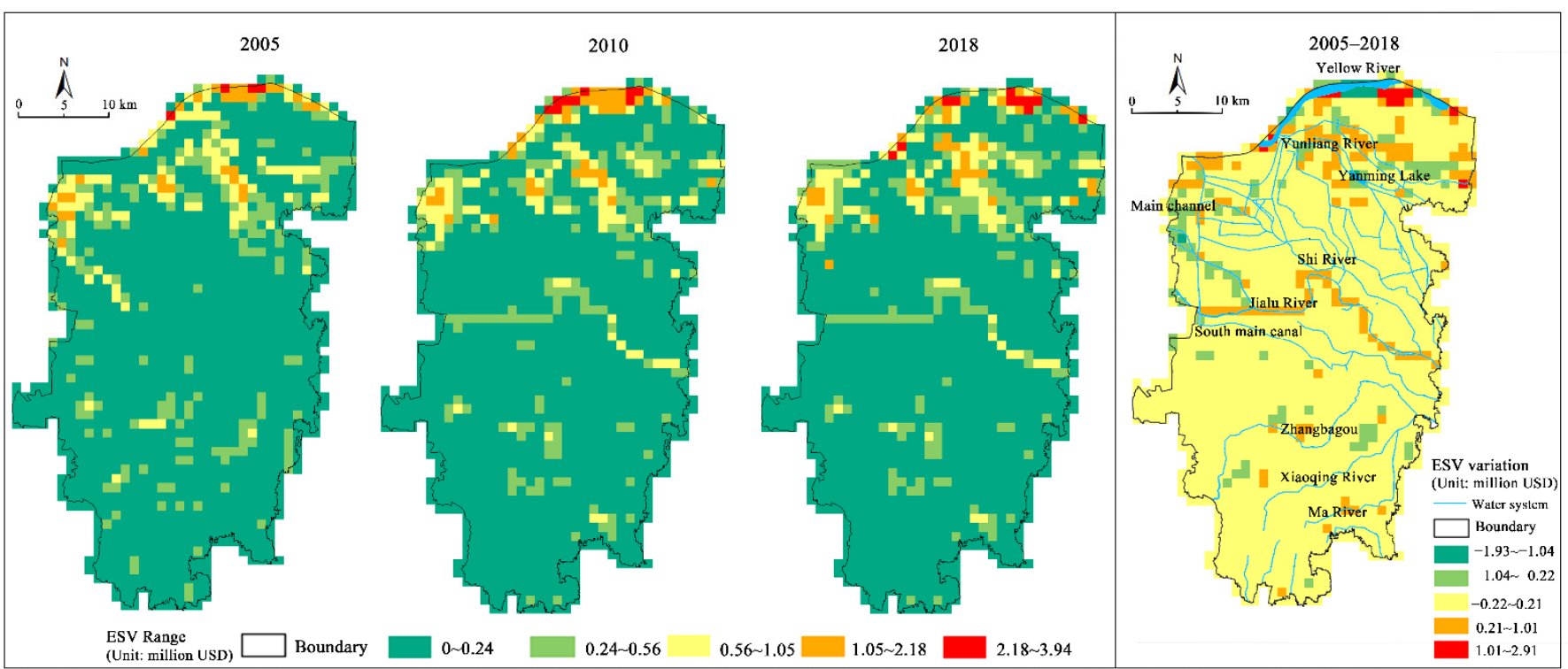

Figure 3. Spatial distribution of ESV and its variation. 
Table 6. The number and proportion of different grading zones of ESV.

\begin{tabular}{|c|c|c|c|c|c|}
\hline \multirow{2}{*}{$\begin{array}{c}\text { ESV Range } \\
\text { (Unit: USD million) }\end{array}$} & \multirow{2}{*}{ Grade } & 2005 & 2010 & 2018 & \multirow{2}{*}{$\begin{array}{c}\text { Average } \\
\text { Percentage/\% }\end{array}$} \\
\hline & & Quantity & Quantity & Quantity & \\
\hline $0-0.24$ & Low-value area & 1213 & 1217 & 1197 & 80.01 \\
\hline $0.24-0.56$ & Lower-value area & 170 & 161 & 169 & 11.03 \\
\hline $0.56-1.05$ & Median zone & 94 & 86 & 95 & 6.07 \\
\hline $1.05-2.18$ & $\begin{array}{c}\text { Higher-value } \\
\text { area }\end{array}$ & 30 & 38 & 39 & 2.36 \\
\hline $2.18-3.94$ & High-value area & 4 & 9 & 11 & 0.53 \\
\hline \multicolumn{2}{|l|}{ Total } & 1511 & 1511 & 1511 & 100 \\
\hline
\end{tabular}

From the perspective of the spatial distribution of ESV changes from 2005 to 2018, the ESV changes were generally between USD -0.22 and 0.21 million, and the areas with an increase of USD 1.00 to 2.91 million only existed in local areas of the Yellow River. In addition, the ESV variation in the Jialu River Basin in the central part was significantly higher than that of the surrounding areas, forming a northwest-southeast belt-shaped area in the entire Zhongmu County. At the same time, the ESV variation in the belt-shaped area had obvious spatial differentiation characteristics: the ESV in the upper reaches of the northwestern is generally in a state of reduction, and the reductions are all more than USD 0.22 million; the opposite is true in the middle and lower reaches of the central and southeastern regions, the growth of ESV both exceeded USD 0.21 million, mainly due to the influence of the "Zhengzhou-Kaifeng integration" policy.

\subsection{ESV's Dynamic Response to Landscape Pattern}

\subsubsection{Landscape Transfer of ESV Changes in Cold/Hot Spots}

From 2005 to 2018, the distribution of ESV hot spots and their landscape shifts were as follows: (1) The northern Yanming Lake and Yellow River areas mainly shifted from cultivated land to waters. (2) There were a small number of scattered hot spots in the central and southern regions, mainly shifting cultivated land to waters and forests, respectively. The distribution of ESV cold spots and their landscape shifts were as follows: (1) Northeast of Zhongmu County, mainly due to the conversion of waters to cultivated land. (2) The Baisha cluster area in the west was mainly converted from waters to cultivated land and cultivated land to construction land (Figure 4).

Synthesizing the landscape shifts in the cold and hot spots in the three periods, it was found that the change in cultivated land to waters and forests was the main area in the hot spots of ESV change. Waters and forests contributed to hydrological regulation, water supply, climate regulation, and other service functions. Therefore, ESV in areas where cultivated land is transferred to waters and forests increased significantly. In the cold spot area where ESV changes, waters were mainly assigned to construction land and cultivated land. This was primarily due to the weak ESV of construction land and food production and consumption, hydrological regulation, soil conservation, biodiversity, and other ecological service functions. Furthermore, the ecological contribution per unit area of cultivated land was much smaller than that of water, so ESV decreased significantly in areas where water was transferred to construction land and cultivated land.

\subsubsection{Spatial Correlation between ESV and Landscape-Level Index}

Table 7 showed that the global Moran's I values of PD, ED, LSI, SHAPE_MN, FRAC_MN, and ESV were all greater than 0 , showing a positive spatial correlation, indicating that the higher the degree of fragmentation of the landscape, the higher the richness of the patch, and the more complex the shape of the patch, the higher the ESV of its neighborhood. The connectivity index, CONTAG, COHESION, and ESV global Moran's I values were all negative and relatively close to 0 , indicating a weak spatial negative correlation with ESV. When the connectivity of the spatial unit is high, the ESV of its neighborhood is low. 


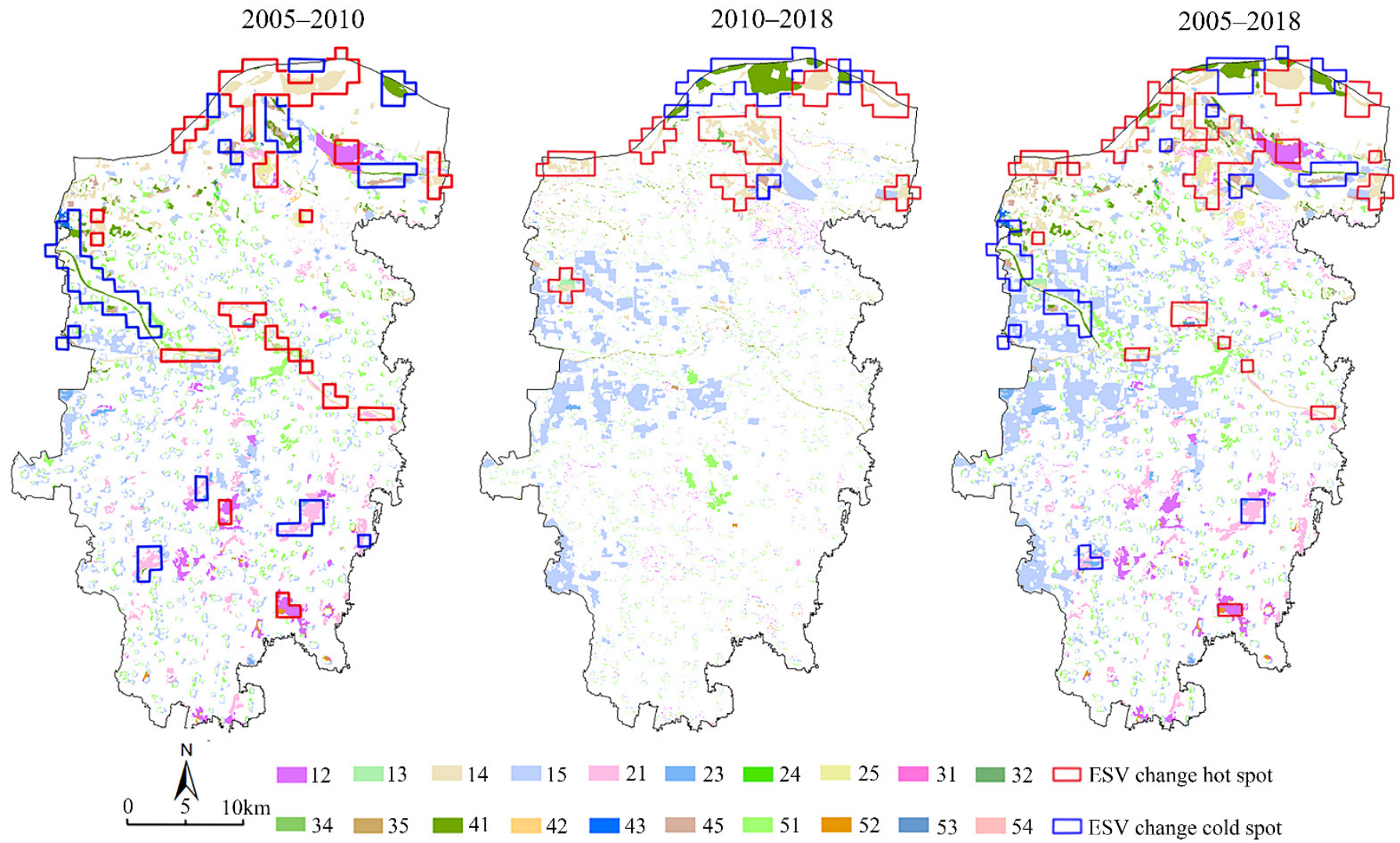

Note: 12: Cropland to forest; 13: Cropland to grassland; 14: Cropland to water; 15: Cropland to construction land; 21: Forest to cropland; 23: Forest to grassland; 24: Forest to water; 25: Forest to construction land; 31: Grassland to cropland; 32: Grassland to forest; 34: Grassland to water; 35: Grassland to construction land; 41: Water to cropland; 42: Water to forest; 43: Waters to grassland; 45: Waters to construction land; 51: Construction land to cropland; 52: Construction land to forest; 53: Construction land to grassland; 54: Construction land to waters

Figure 4. Overlay analysis of ESV changes in cold/hot spots and landscape shifts.

Table 7. Global Moran's I of ESV and landscape level pattern index.

\begin{tabular}{cccc}
\hline Landscape Level Index & $\mathbf{2 0 0 5}$ & $\mathbf{2 0 1 0}$ & $\mathbf{2 0 1 8}$ \\
\hline PD & 0.120 & 0.101 & 0.140 \\
ED & 0.118 & 0.080 & 0.135 \\
LSI & 0.118 & 0.080 & 0.135 \\
SHAPE_MN & 0.067 & 0.027 & 0.061 \\
FRAC_MN & 0.083 & 0.039 & 0.050 \\
CONTAG & -0.021 & -0.002 & -0.019 \\
COHESION & -0.181 & -0.123 & -0.054 \\
\hline
\end{tabular}

The global Moran's I of ESV and landscape level pattern index in 2005, 2010, and 2018 were obtained through the GeoDa software. After 999 random permutations, all $p$-values were 0.001, which shows that the spatial autocorrelation between ESV and landscape index is significant under $99.9 \%$ confidence.

The LISA clustering map of PD, ED, LSI, SHAPE_MN, FRAC_MN, and ESV was mainly high-high clusters and low-low clusters. Figure 5 showed that the high-high clusters of the above index and ESV were primarily located in the Yanming Lake, the Yellow River, and the paddy fields and reservoir pond areas in the northwest corner of Zhongmu County. It is shown that the higher the abundance of these three landscape patches, the higher the ESV of the neighborhood. Therefore, the number and shape complexity of landscape patches in Yanming Lake, the Yellow River, and the northwest corner of Zhongmu County can be increased to improve the ESV of Zhongmu County effectively. 


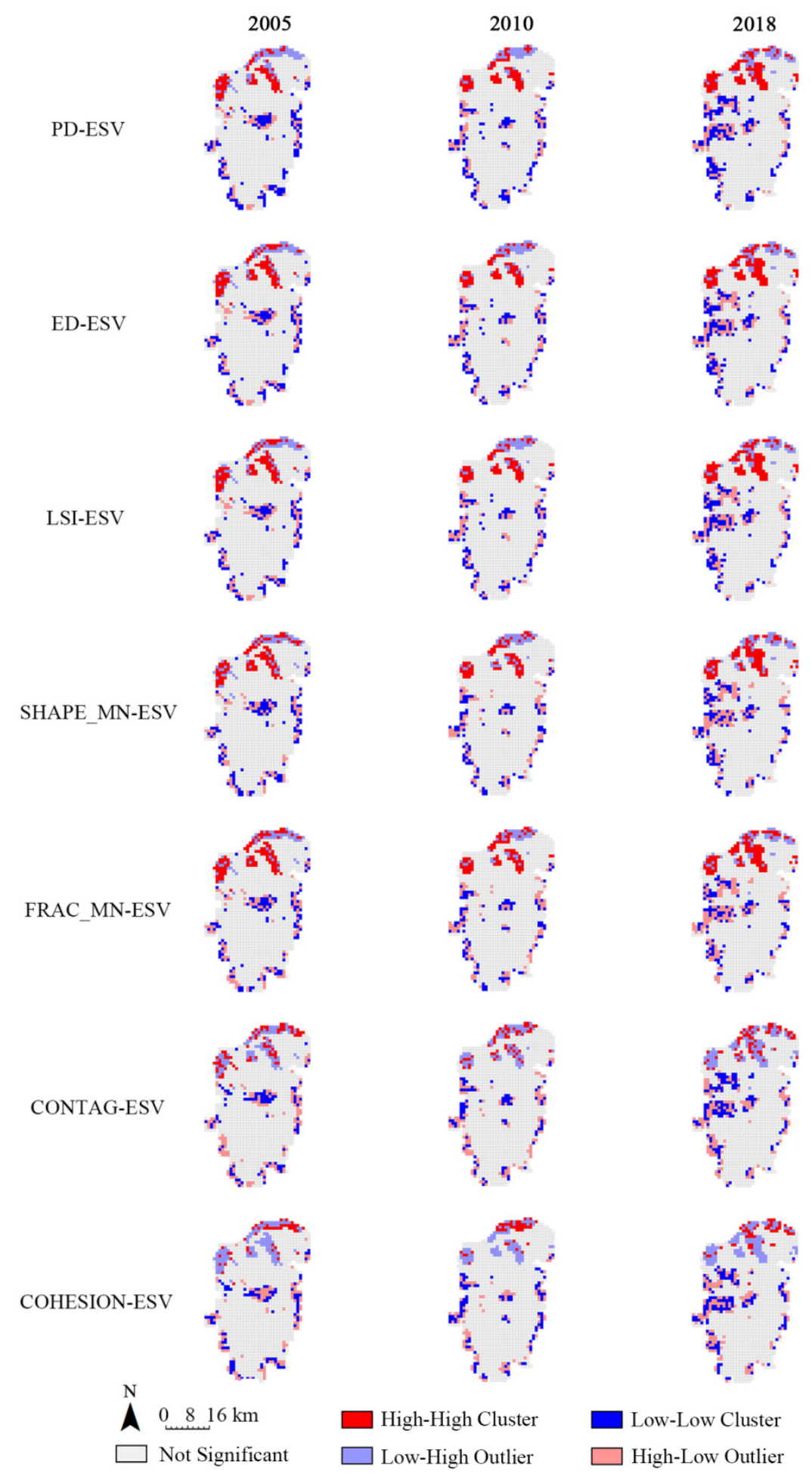

Figure 5. The LISA clustering map of ESV and landscape pattern metrics of ESV and landscape pattern metrics.

The LISA clustering map of CONTAG, COHESION, and ESV mainly focused on the spatial aggregation modes of low-high outliers and high-low outliers. The low-high outliers were mainly distributed in the north, and the high-low outliers were mainly distributed in the south. The distributions of the high-high clusters and low-low clusters of PD, ED, LSI, SHAPE_MN, FRAC_MN, and ESV were consistent, which means that the higher the connectivity of landscape patches in the Yellow River, Yanming Lake and the northwest region, the lower the overall ESV, which further proved that attention should be focused on 
increasing the richness and complexity of the three regional landscape patches to achieve an efficient increase in ESV.

\section{Discussion}

\subsection{Landscape Pattern and ESV Spatio-Temporal Changes}

4.1.1. Landscape Elements and ESV

From 2005 to 2018, as the areas of canal, reservoir pond, and woodland increased by $5.36 \mathrm{~km}^{2}, 16.40 \mathrm{~km}^{2}$, and $8.03 \mathrm{~km}^{2}$, respectively, and the areas of dry land, paddy fields and gardens decreased by $84.24 \mathrm{~km}^{2}, 43.98 \mathrm{~km}^{2}$, and $20.37 \mathrm{~km}^{2}$, respectively. The ESV of hydrological regulation was compared with soil conservation and gas regulation functions, the only performance was positive growth. At the same time, through the superposition analysis of the ESV variation cold, hot spots, and landscape transfer matrix maps, it is found that the ESV in the area where the cultivated land was transferred to the water area and the forest was significantly increased. The ESV, where the water was transferred to the construction land and the cultivated land, was reduced substantially. The above conclusions fully reflected that the changes in elements in the landscape pattern of Zhongmu County had a significant impact on ESV. This was more consistent with previous research conclusions: For example, Hou et al. [39] found that the conversion of forest land to construction land in $\mathrm{Xi}^{\prime}$ an had the greatest negative impact on ESV, followed by the conversion of grassland to construction land; Assefa et al. [40] found that the area of Bahir Dar City and its surrounding wetlands and water bodies in Ethiopia decreased by 1618 hectares, resulting in a reduction in the total ESV of USD 8.9 million, and the reduction in ESV had a negative impact on the local climate, waste management and the livelihoods of poor communities.

\subsubsection{Landscape Index and ESV}

In the Yanming Lake, Yellow River in the north, the paddy fields, and reservoir pond areas in the northwestern corner in Zhongmu County, ESV was positively correlated with PD, ED, SHAPE_MN, FRAC_MN, and LSI, and negatively correlated with CONTAG and COHESION, indicating that the more landscape patches in the Yanming Lake, Yellow River and northwest corner, the higher the complexity and the higher the ESV. Lin et al. [41] discussed in the study of Guangdong-Hongkong-Macao Greater Bay Area that abundant patch types in the landscape were conducive to improving soil conservation ability, so ESV also increased correspondingly, while enhanced connectivity was not conducive to maintaining soil conservation ability, so ESV was reduced. In addition, other scholars also had the opposite conclusion. For example, through correlation analysis, Gu et al. [42] found that ESV in Lancang County was negatively correlated with PD and LSI, but positively correlated with CONTAG; Qiu et al. [43] found in Fuyang City that the total ESV negatively correlated with ED, PD, LSI, and SHDI, suggesting that landscape fragmentation had an adverse impact on the overall ESV in Fuyang City. Based on the above research conclusions, it can be concluded that the impact of landscape pattern index on ESV is complicated. Cen et al. [19] also proved a non-linear and complex dynamic relationship between ESV and landscape pattern index in the study of the south bank area of Hangzhou Bay. Therefore, the correlation and interaction degree of ESV and the landscape pattern index are different in different research areas or different spaces in the same research area. It is necessary to analyze other regions to propose targeted landscape pattern control strategies, which effectively improve the level of regional ES.

\subsection{Driving Force Analysis}

Most studies have shown that policy factors are the main driving forces for landscape patterns and ESV changes: Raviv et al. [44] found that in the Serekamer Mountain Biosphere Reserve, although wildfires and land cover changes affect the ecosystem, good land restoration programs increase the value of ecosystem services by $30-50 \%$; Mendoza-González et al. [45] proved that the development of tourism policies in the cen- 
tral Gulf of Mexico led to the loss of the value of ecological services such as coastal protection. In this study, the implementation of urban planning policies and ecological policies at different levels during 2005-2018 was also the main driving force for the changes in landscape patterns and ES in Zhongmu County.

In terms of urban planning policies, the Zhengzhou-Kaifeng integration played an important role in promoting the development of Zhongmu County. In 2005, when the concept of Zhengzhou-Kaifeng integration was formed, Zhongmu County's arable land, mainly dry land and paddy fields accounted for $36.70 \%$, and construction land accounted for only $4.54 \%$. From 2005 to 2018, the Zhengzhou-Kaifeng integration was promoted by the state [25]. In 2016 the National Development and Reform Commission officially approved Zhengzhou as a national central city, promoting Zhengzhou to lead the construction of a metropolitan area, which further promoted the urbanization development process of Zhongmu County in the Zhengzhou-Kaifeng integration [46]. During this period, Zhongmu County initially established a comprehensive transportation system that coordinated with the Zhengzhou-Kaifeng Integration strategy. At the same time, construction land was continuously increasing, such as industrial parks and residential communities. The urban development pattern of "three axes, three districts, and multiple clusters" was initially formed [26]. This further promoted the changes in the landscape pattern in Zhongmu County in the Zhengzhou-Kaifeng integration. In 2018, the proportion of cultivated land decreased to $32.47 \%$. The ratio of construction land rapidly increased to $8.64 \%$, which led to a negative growth in soil conservation and gas regulation functions that have contributed much to the county's ecological value.

In terms of environmental policies, the concepts emphasized by the central government, such as "ecological civilization", "green development", "ecological city", and "ecological red line", provide national-level policy guarantees for the sustainable development of the ecological environment in Zhongmu County. From 2005 to 2018, the Outline of the Central Plains Urban Agglomeration Overall Development Plan proposed that the Zhengzhou-Kaifeng integration area build green corridors on both sides of the main arterial roads, construct forests and greenbelt ecological adjustment zones in feasible areas, and develop urban agriculture and sightseeing agriculture to realize the ecological docking between Zhengzhou and Kaifeng [47,48]. The Zhengzhou Municipal Government successively implemented the Zhengzhou City Master Plan (2010-2020), Zhengzhou City Green Space System Planning (2013-2030), Zhengzhou National Central City Ecological Construction Plan (2016-2025), Zhengzhou Forestry Ecological Construction Implementation Plan in 2017, and the Zhengzhou City Ecological Protection and Construction Planning (2017-2035) which put forward construction along the Yellow River ecological cultural tourism industry area, the Yellow River ecological zone in the north, the Yellow River ecological wetland landscape zone, the ecological barrier along the Yellow River zone in the north of Zhengzhou, and the Yellow River ecological conservation and ecological culture development belt, respectively, by returning farmland to forest, widening the drainage of the levee protection, ecological hydrating and other measures. This greatly improved the ESV in the Yellow River Basin and Yanming Lake region in the north, which is also the reason why the area with the increase in ecological value as high as USD 1.00 million to USD 2.91 million only existed in the Yellow River region, and the high-value accumulation area of the total ESV was mainly distributed in the north and the range was increasing.

\subsection{Optimization Measures and Outlook}

This study analyzed the spatial and temporal changes in landscape patterns and ecosystem service values in the study area in the context of integrated urban development. Based on the results of the study, the following optimization measures are proposed for the future, to provide recommendations for the future by means of planning policies and strategies.

(1) Enhance the development the quality of green infrastructure. Improve the development level of green infrastructures such as rivers, wetlands, and woodlands to 
enhance the function of ecosystem services such as hydrology, climate, and soil in the region and effectively increase the total amount of ESV;

(2) Control the unlimited expansion of construction land and strengthen the core ecological infrastructure. We should strictly control the unlimited expansion of construction land, optimize the layout of construction land, strengthen the intensive use, and avoid the massive erosion of arable land, water and other high-quality landscapes. At the same time, provide full play to the core advantages of the central city and strengthen the construction of "ecological green core: Zhengzhou-Kaifeng Central Park" and "ecological green core: comprehensive parks, special parks, community parks, pocket parks, etc." Form a comprehensive park system to ensure the high quality of life for the high-density population in the central region and the stable growth of ESV;

(3) Promote high-quality development of watershed ecological reserves. The Yellow River basin is the most important ecological source [49]. Further, promote the highquality development of the ecological reserve along the Yellow River. Gradually improve the landscape pattern of the Yellow River basin with "wetland-protection forest-agricultural land", and restore the value of the Yellow River ecosystem services.

\subsection{Limitation}

Several limitations in this paper should be acknowledged. Firstly, the resolution of the acquired remote sensing interpretation data were limited, and unnecessary errors may occur due to the vacancy of the data itself. Secondly, the consideration of social and human factors was relatively inadequate. In the future, the accuracy of remote sensing interpretation data and social and human factors should be considered as comprehensively as possible.

\section{Conclusions}

Based on the remote sensing interpretation data and socioeconomic data of Zhongmu County in 2005, 2010 and 2018, this study analyzed the spatial pattern dynamics of the overall and various types of landscapes in combination with the landscape index, and analyzed the dynamic process of ecosystem service values in Zhongmu County based on the equivalent factor method. Finally, the spatial relationship between landscape patterns and ecosystem services was analyzed comprehensively, and the influence of policy drivers was systematically sorted. Ecological problems and optimization measures in Zhongmu County were proposed in response to the research results. The conclusions of this paper are as follows:

(1) Changes in the total value of ecosystem services. The total value of ecosystem services in Zhongmu County in 2005, 2010 and 2018 showed a fluctuating trend of first increasing and then decreasing, with the total value increasing by USD 10.05 million, and the ecological environment construction achieved certain results. Spatially, the low-value area was the main area $(80.01 \%)$, the high-value area was only in the local area of the Yellow River (0.53\%), and the higher-value area was mainly in the Yellow River, Yanming Lake, and the paddy fields and reservoir ponds $(2.36 \%)$ in the northwest corner. The spatial aggregation pattern of ecological values has a border effect: the high-high clusters area was mainly at the northern Yellow River border, while the low-low clusters area was at the east-west border, and there is an obvious trend of expansion to the east;

(2) Changes in the ecosystem service values of various landscapes. The ecosystem service value of dry lands always remains the highest, with an average contribution of $37.46 \%$ to the overall value, and was the most dominant landscape in Zhongmu County in maintaining ecosystem service value, followed by reservoir ponds $(14.65 \%)$ and canals $(10.51 \%)$, with changes mainly related to the increase or decrease in the corresponding landscape area and value coefficients;

(3) Changes in ecosystem service values of different service functions. The service functions with a higher average contribution to the ecological value of Zhongmu 
County were hydrological regulation (33.64\%), soil conservation (12.71\%) and climate regulation $(10.16 \%)$, among which only the ecological value of hydrological regulation had positive growth;

(4) Through the overlay analysis of the cold, hot spot and landscape transfer matrix mapping of the amount of ecosystem service change from 2005 to 2010, 2010 to 2018 and 2005 to 2018, it was found that the value of ecosystem services in the areas where cropland was transferred to waters and forests increased significantly, and the value of ecosystem services in the areas where waters were transferred to construction land and cropland decreased significantly. Therefore, we can focus on increasing watershed and forest in the landscape regulation to improve the ecosystem service value;

(5) Through bivariate spatial autocorrelation analysis, it is found that the ecosystem service value can be effectively increased by enriching the landscape types and increasing the number and complexity of landscape patches in the region.

The study had important implications for the planning and management policies for Zhongmu County and other urban developing regions: (1) urban integration areas should strictly limit the expansion of construction land, optimize the layout of construction land to enhance its intensive use, and increase the plot ratio and use efficiency on the limited construction land; (2) improve the development level of green infrastructures such as rivers, wetlands and woodlands, so as to enhance the function of ecosystem services such as hydrology, climate and soil in the region and effectively increase the total amount of ESV.

Author Contributions: Conceptualization, Y.L., X.Z., H.L. and H.X.; data curation, X.Z., H.X.; funding acquisition, Y.L.; investigation, X.Z.; project administration, Y.L.; resources, Y.L. and G.T.; supervision, Y.L., Y.Y., G.T. and G.K.; validation, H.L., G.K.; writing-review and editing, X.Z., H.L., G.K., Y.L., Y.Y. and G.T. All authors have read and agreed to the published version of the manuscript.

Funding: This research was funded by the National Natural Science Foundation of China (31600579); 2020 Training Program for Young Backbone Teachers in Higher Education Institutions in Henan Province "Impact of Multi-scale Green Space Planning and Design on Public Health" (2020GGJS049); Henan International Cooperation Research Project "Research on Planning and Design Strategies of Multi-scale Green Infrastructure in Central Plains Urban Agglomeration" (HNGD2021035) and the International Joint Laboratory of Landscape Architecture in Henan Province.

Data Availability Statement: The data presented in this study are available on request from the first author.

Acknowledgments: The authors would like to thank the support of the International Joint Laboratory of Landscape Architecture, Henan Agricultural University, for their infinite help.

Conflicts of Interest: The authors declare no conflict of interest.

\section{Appendix A}

Table A1. Description of landscape classification in Zhongmu County.

\begin{tabular}{ccc}
\hline First Classification & Secondary Classification & \multicolumn{1}{c}{ Description } \\
\hline Cultivated land & Paddy field & $\begin{array}{l}\text { Irrigated arable land for growing rice, lotus root, and other } \\
\text { aquatic crops, including arable land where rice and dry land } \\
\text { crops are rotated. } \\
\text { Cultivated land that relies on natural precipitation to grow } \\
\text { crops and cultivated land that mainly grows vegetables. }\end{array}$ \\
\hline
\end{tabular}


Table A1. Cont.

\begin{tabular}{|c|c|c|}
\hline First Classification & Secondary Classification & Description \\
\hline Forest & $\begin{array}{l}\text { Woodland } \\
\text { Garden plot }\end{array}$ & $\begin{array}{l}\text { Natural forests and artificial forests (including timber } \\
\text { forests, economic forests, shelterbelts, etc.) with a canopy } \\
\text { closure greater than } 30 \% \text {, low forest land and shrubland } \\
\text { with a canopy closure greater than } 40 \% \text {, and a height of } \\
\text { fewer than } 2 \mathrm{~m} \text {. } \\
\text { Unformed forest afforestation land, site, nursery and } \\
\text { orchard, mulberry garden, tea garden, hot cropping forest } \\
\text { garden, etc. }\end{array}$ \\
\hline Grassland & High-coverage grassland & $\begin{array}{l}\text { Natural grassland, improved grassland and mowing grass } \\
\text { with a coverage }>50 \% \text {. Generally, the water condition is } \\
\text { good and the growth is dense. }\end{array}$ \\
\hline Water area & $\begin{array}{c}\text { Canal } \\
\text { Reservoir pond } \\
\text { Bottomland }\end{array}$ & $\begin{array}{l}\text { Naturally formed or artificially excavated rivers and } \\
\text { artificial canals. } \\
\text { The land below the perennial water level in the artificially } \\
\text { constructed water storage area. } \\
\text { The land between the water level of rivers and lakes during } \\
\text { the normal period and the water level of the flood period. }\end{array}$ \\
\hline Construction land & $\begin{array}{l}\text { Urban land } \\
\text { Rural residential land } \\
\text { Other construction lands }\end{array}$ & $\begin{array}{l}\text { Large, medium and small cities and built-up areas above } \\
\text { counties and towns. } \\
\text { Independent of rural settlements outside of cities and towns. } \\
\text { Lands for factories and mines, large industrial areas, oil } \\
\text { fields, saltworks, quarries, etc., as well as traffic roads, } \\
\text { airports, and special land. }\end{array}$ \\
\hline
\end{tabular}

Table A2. Landscape pattern index and its ecological significance.

\begin{tabular}{|c|c|}
\hline Landscape Pattern Index & Ecological Significance \\
\hline Percentage of Landscape (PLAND) & $\begin{array}{l}\text { Reflects the relative proportion of a certain landscape type to the entire landscape } \\
\text { area [50]. }\end{array}$ \\
\hline Largest Patch Index (LPI) & $\begin{array}{l}\text { It reflects the proportion of the largest patch in the landscape area and determines } \\
\text { the dominant type in the landscape [51]. }\end{array}$ \\
\hline Edge Density (ED) & $\begin{array}{l}\text { Reflect the degree of differentiation or fragmentation of the overall landscape } \\
\text { patch [52]. }\end{array}$ \\
\hline Mean Patch Fractal Dimension (FRAC_MN) & $\begin{array}{l}\text { Reflect the complexity of the patch shape of the landscape type. The larger the } \\
\text { value, the greater the space occupied by the landscape type, and the more complex } \\
\text { its shape [53]. }\end{array}$ \\
\hline Mean Patch Size (SHAPE_MN) & $\begin{array}{l}\text { Reflects the degree of deviation of the plaque shape from the standard shape } \\
\text { (round or square). When all patches in the landscape are square, the value is } 1 \text {; } \\
\text { when the shape of the patches deviates from the square, the value increases [54]. }\end{array}$ \\
\hline Patch Density (PD) & $\begin{array}{l}\text { Reflecting the number of patches per unit area and characterizing the complexity } \\
\text { of landscape spatial structure, is an important indicator for evaluating landscape } \\
\text { fragmentation [55]. }\end{array}$ \\
\hline Patch Cohesion Index (COHESION) & $\begin{array}{l}\text { Reflecting the physical connectivity of patches, the smaller the value, the more } \\
\text { scattered the landscape patches }[56,57] \text {. }\end{array}$ \\
\hline Landscape Shape Index (LSI) & $\begin{array}{l}\text { Reflecting the overall geometric complexity of the landscape, the larger the value, } \\
\text { the longer and irregular the boundary of the patch, the more discrete the patch, } \\
\text { that is, the higher the complexity or fragmentation of the landscape [58]. }\end{array}$ \\
\hline Contagion Index (CONTAG) & $\begin{array}{l}\text { Reflects the degree of agglomeration or spreading trend of different plaque types. } \\
\text { To measure to what extent landscapes are aggregated or clumped as a percentage } \\
\text { of the maximum possible [59]. }\end{array}$ \\
\hline Shannon's Diversity (SHDI) & $\begin{array}{l}\text { A measure of patch diversity in a landscape, which is determined by both the } \\
\text { number of different patch types and the proportional distribution of area among } \\
\text { patch types [60]. }\end{array}$ \\
\hline
\end{tabular}


Table A3. Ecosystem service equivalent value per unit area in China's terrestrial ecosystem (2015).

\begin{tabular}{|c|c|c|c|c|c|c|c|c|c|c|c|c|}
\hline & $\begin{array}{l}2 \\
0 \\
0 \\
0 \\
0 \\
0 \\
0 \\
0 \\
0 \\
0\end{array}$ & & 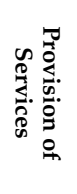 & & & & & & & 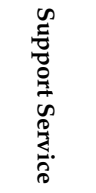 & & 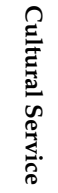 \\
\hline 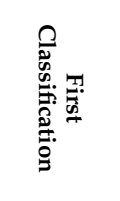 & 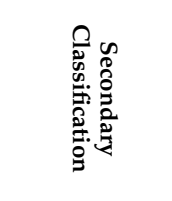 & 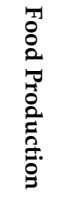 & 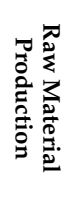 & 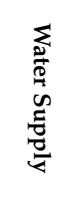 & 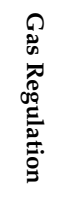 & 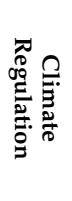 & 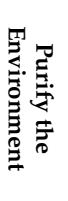 & 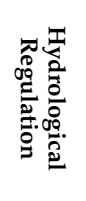 & 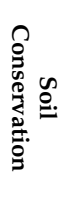 & 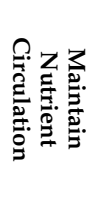 & 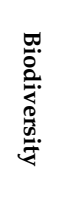 & 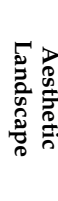 \\
\hline \multirow{2}{*}{ Farmland } & Dry land & 0.85 & 0.40 & 0.02 & 0.67 & 0.36 & 0.10 & 0.27 & 1.03 & 0.12 & 0.13 & 0.06 \\
\hline & Paddy field & 1.36 & 0.09 & -2.63 & 1.11 & 0.57 & 0.17 & 2.72 & 0.01 & 0.19 & 0.21 & 0.09 \\
\hline \multirow{4}{*}{ Forest } & $\begin{array}{l}\text { Coniferous } \\
\text { forest }\end{array}$ & 0.22 & 0.52 & 0.27 & 1.70 & 5.07 & 1.49 & 3.34 & 2.06 & 0.16 & 1.88 & 0.82 \\
\hline & $\begin{array}{c}\text { Coniferous } \\
\text { and } \\
\text { broad-leaved } \\
\text { mixed }\end{array}$ & 0.31 & 0.71 & 0.37 & 2.35 & 7.03 & 1.99 & 3.51 & 2.86 & 0.22 & 2.60 & 1.14 \\
\hline & Broadleaf & 0.29 & 0.66 & 0.34 & 2.17 & 6.50 & 1.93 & 4.74 & 2.65 & 0.20 & 2.41 & 1.06 \\
\hline & Shrub wood & 0.19 & 0.43 & 0.22 & 1.41 & 4.23 & 1.28 & 3.35 & 1.72 & 0.13 & 1.57 & 0.69 \\
\hline \multirow{3}{*}{ Grassland } & Grassland & 0.10 & 0.14 & 0.08 & 0.51 & 1.34 & 0.44 & 0.98 & 0.62 & 0.05 & 0.56 & 0.25 \\
\hline & $\begin{array}{l}\text { Scrub- } \\
\text { grassland }\end{array}$ & 0.38 & 0.56 & 0.31 & 1.97 & 5.21 & 1.72 & 3.82 & 2.40 & 0.18 & 2.18 & 0.96 \\
\hline & Meadow & 0.22 & 0.33 & 0.18 & 1.14 & 3.02 & 1.00 & 2.21 & 1.39 & 0.11 & 1.27 & 0.56 \\
\hline Wetlands & Wetlands & 0.51 & 0.50 & 2.59 & 1.90 & 3.60 & 3.60 & 24.23 & 2.31 & 0.18 & 7.87 & 4.73 \\
\hline \multirow{2}{*}{ Desert } & Desert & 0.01 & 0.03 & 0.02 & 0.11 & 0.10 & 0.31 & 0.21 & 0.13 & 0.01 & 0.12 & 0.05 \\
\hline & Bare land & 0.00 & 0.00 & 0.00 & 0.02 & 0.00 & 0.10 & 0.03 & 0.02 & 0.00 & 0.02 & 0.01 \\
\hline \multirow{2}{*}{ Waters } & Water system & 0.80 & 0.23 & 8.29 & 0.77 & 2.29 & 5.55 & 102.24 & 0.93 & 0.07 & 2.55 & 1.89 \\
\hline & Glacier snow & 0.00 & 0.00 & 2.16 & 0.18 & 0.54 & 0.16 & 7.13 & 0.00 & 0.00 & 0.01 & 0.09 \\
\hline
\end{tabular}

\section{References}

1. Costanza, R.; d'Arge, R.; De, G.R.; Farber, S.; Grasso, M.; Hannon, B.; Limburg, K.; Naeem, S.; O'Neill, R.V.; Paruelo, J.; et al. The value of the world's ecosystem services and natural capital. Nature 1997, 387, 253-260. [CrossRef]

2. Costanza, R.; De, G.R.; Sutton, P.; Ploeg, S.; Anderson, S.J.; Kubiszewski, I.; Farber, R.S.; Turner, K. Changes in the global value of ecosystem services. Glob. Environ. Chang. 2014, 26, 152-158. [CrossRef]

3. Groot, R.S.; Wilson, M.A.; Boumans, R.M.J. A typology for the classification, description and valuation of ecosystem functions, goods and services. Ecol. Economics. 2002, 41, 393-408. [CrossRef]

4. Ojea, E.; Martin-Ortega, J.; Chiabai, A. Defining and classifying ecosystem services for economic valuation: The case of forest water services. Environ. Sci. Policy 2012, 19-20, 1-15. [CrossRef]

5. Ouyang, Z.; Wang, R.; Zhao, J. Ecosystem service function and its ecological economic value evaluation. J. Appl. Ecol. 1999, 5, 635-640.

6. Redford, K.H.; Adams, W.M. Payment for ecosystem services and the challenge of saving nature. Conserv. Biol. 2009, $23,785-787$. [PubMed]

7. Huang, L.; Cao, W.; Xu, X.; Fan, J.; Wang, J. Linking the benefits of ecosystem services to sustainable spatial planning of ecological conservation strategies. J. Environ. Manag. 2018, 222, 385-395. [CrossRef] [PubMed]

8. Li, T.; Zhang, Q.; Zhang, Y. Modelling a Compensation Standard for a Regional Forest Ecosystem: A Case Study in Yanqing District, Beijing, China. Int. J. Environ. Res. Public Health 2018, 15, 565. [CrossRef] [PubMed]

9. Peng, J.; Yang, Y.; Liu, Y.; Hu, Y.; Du, Y. Linking ecosystem services and circuit theory to identify ecological security patterns. Sci. Total. Environ. 2018, 644, 787-790. [CrossRef]

10. Shi, P.; Zhang, X.; Luo, J.; Zhang, X. Response of Ecological Services Value to Land Use Change in the Shiyang River Basin: A Case Study in Wuwei Region. Adv. Mater. Res. 2012, 518-523, 5116-5120. [CrossRef]

11. $\mathrm{Su}, \mathrm{C} . ; \mathrm{Fu}, \mathrm{B}$. The relationship between landscape pattern and ecological process and its impact on ecosystem services. J. Nat. 2012, 34, 277.

12. Renetzeder, C.; Schindler, S.; Peterseil, J.; Prinz, M.A.; Mücher, S.; Wrbka, T. Can we measure ecological sustainability? Landscape pattern as an indicator for naturalness and land use intensity at regional, national and European level. Ecol. Indic. 2009, 10, 39-48. [CrossRef]

13. Hof, J.; Flather, C. Key Topics In Landscape Ecology: Optimization Of Landscape Pattern; Cambridge University Press: Cambridge, UK, 2007; pp. 39-61.

14. Li, L.; Wu, D.; Liu, Y. Research hotspots and trends of land use and ecosystem services at home and abroad-Based on CiteSpace measurement analysis. Res. Soil Water Conserv. 2020, 27, 396-404. 
15. Shen, G.; Yang, X.; Jin, Y.; Luo, S.; Zhou, Q. Land Use Changes in the Zoige Plateau Based on the Object-Oriented Method and Their Effects on Landscape Patterns. Remote. Sens. 2019, 12, 14. [CrossRef]

16. Nelson, E.; Mendoza, G.; Regetz, J.; Polasky, S.; Tallis, H.; Cameron, D.R.; Chan, K.M.A.; Daily, G.C.; Goldstein, J.; Kareiva, P.M.; et al. Modeling Multiple Ecosystem Services, Biodiversity Conservation, Commodity Production, and Tradeoffs at Landscape Scales. Front. Ecol. Environ. 2009, 7, 4-11. [CrossRef]

17. Grêt-Regamey, A.; Rabe, S.E.; Crespo, R.; Crespo, R.; Lautenbach, S.; Ryffel, A.; Schlup, B. On the importance of non-linear relationships between landscape patterns and the sustainable provision of ecosystem services. Landsc. Ecol. 2014, 29, 201-212. [CrossRef]

18. Soy-Massoni, E.; Langemeyer, J.; Varga, D.; Sáez, M.; Pintó, J. The importance of ecosystem services in coastal agricultural landscapes: Case study from the Costa Brava, Catalonia. Ecosyst. Serv. 2016, 17, 43-52. [CrossRef]

19. Cen, X. Association Analysis and Optimization of Land Use Landscape Pattern and Ecosystem Service Value; Zhejiang University: Hangzhou, China, 2016.

20. Guo, M.; Shu, S.; Ma, S.; Wang, L. Using high-resolution remote sensing images to explore the spatial relationship between landscape patterns and ecosystem service values in regions of urbanization. Environ. Sci. Pollut. Res. 2021, 1-3. [CrossRef]

21. Feng, Y.; Zhu, J.; Zeng, L.; Xiao, W. Ecosystem service value profit and loss prediction under county land use changes: A case study in Banan District, Chongqing City. Chin. J. Ecol. Sci. 2021, 9, 1-13.

22. National Bureau of Statistics. Available online: http://www.stats.gov.cn/tjsj/ndsj/ (accessed on 14 August 2021).

23. Xia, H.; Ge, S.; Zhang, X.; Lei, Y.; Liu, Y. Spatiotemporal Dynamics of Green Infrastructure in an Agricultural Peri-Urban Area: A Case Study of Baisha District in Zhengzhou, China. Land 2021, 10, 801. [CrossRef]

24. Lei, Y. Deepen the research on the integration of Zhengzhou and Kaifeng under the background of Zhengzhou central city construction. Times Econ. Trade 2018, 18, 18-19.

25. Cui, Y.; Li, G. Research on the in-depth promotion of Zhengzhou and Kaifeng integration. J. Hubei Univ. Econ. Humanit. Soc. Sci. Ed. 2013, 10, 24-25.

26. Zhongmu County People's Government. Available online: http://www.zhongmu.gov.cn/sitesources/zmxzf/page_pc/zwgk/ tzgg/articlef9acda8975ee49efb5f5a8740fa56688.html (accessed on 8 June 2016).

27. Yinkfu, N.N.; Mbue, I.N. Estimation for Groundwater Balance Based on Recharge and Discharge: A Tool for Sustainable Groundwater Management, Zhongmu County Alluvial Plain Aquifer, Henan Province, China. J. Am. Sci. 2009, 5, 83-90.

28. Nan, J.; Xiao, X. Analysis of Land Use in Jining City. E3S Web of Conferences. EDP Sci. 2020, 198, 04024.

29. Lv, C.; Wang, J.; Li, Y.; He, T. Land use change and its effects on eco-environment in Bashang area of Hebei province. SPIE Remote. Sens. 2005, 5983, 59830J.

30. Xie, G.; Lu, C.; Leng, Y.; Zheng, D.; Li, S. Value evaluation of ecological assets in the Qinghai-Tibet Plateau. J. Nat. Resour. 2003, $18,189-195$.

31. Xie, G.; Zhang, C.; Zhang, C.; Xiao, Y.; Lu, C. The value of ecosystem services in China. Resour. Sc. 2015, 37, 1740-1746.

32. Duan, Y.; Lei, Y.; Ma, G.; Wu, B.; Tian, G. Temporal and spatial changes of ecosystem service value in Zhengzhou City. J. Zhejiang AF Univ. 2017, 34, 511-519.

33. Zhang, Q.; Gao, M.; Yang, L.; Cheng, C.; Sun, Y.; Wang, J. Spatial structure of ecological land and changes in ecosystem service value in the nine districts of the main city of Chongqing from 1988 to 2013. Acta Ecol. Sin. 2017, 37, 566-575.

34. Hu, M.; Li, T.; Wang, F.; Jiao, M.; Li, M.; Xia, B. Spatio-temporal changes in ecosystem service value in response to land-use/cover changes in the Pearl River Delta. Resour. Conserv. Recycl. 2019, 149, 106-114. [CrossRef]

35. Dormann, C.F.; Mcpherson, J.M.; Araújo, M.B.; Bivand, R.; Bolliger, J.; Carl, G.; Davies, R.G.; Hirzel, A.; Jetz, W.; Kissling, W.D. Methods to account for spatial autocorrelation in the analysis of species distributional data: A review. Ecography 2007, 30, 609-628. [CrossRef]

36. Zhang, J.Q.; Gu, J.; Ma, X.C.; Liu, D.-Q. GeoDA-based spatial correlation analysis of landscape fragmentation in Bailongjiang Watershed of Gansu. Chin. J. Ecol. 2018, 37, 1476-1483.

37. Xie, H.; Kung, C.-C.; Zhao, Y. Spatial disparities of regional forest land change based on ESDA and GIS at the county level in Beijing-Tianjin-Hebei area. Front. Earth Sci. 2012, 6, 445-452. [CrossRef]

38. Zhao, H.; Duan, X.; Stewart, B.; You, B.; Jiang, X. Spatial correlations between urbanization and river water pollution in the heavily polluted area of Taihu Lake Basin, China. J. Geogr. Sci. 2013, 23, 735-752. [CrossRef]

39. Hou, L.; Wu, F.; Xie, X. The spatial characteristics and relationships between landscape pattern and ecosystem service value along an urban-rural gradient in Xi'an city, China. Ecol. Indic. 2020, 108, 105720. [CrossRef]

40. Assefa, W.W.; Eneyew, B.G.; Wondie, A. The impacts of land-use and land-cover change on wetland ecosystem service values in peri-urban and urban area of Bahir Dar City, Upper Blue Nile Basin, Northwestern Ethiopia. Ecol. Process. 2021, 10, 1-18. [CrossRef]

41. Lin, M.; Zhou, R.; Zhong, L. Research on changes in ecosystem services in the Guangdong-Hong Kong-Macao Greater Bay Area based on changes in landscape pattern. J. Guangzhou Univ. Nat. Sci. Ed. 2019, 18, 87-95.

42. Gu, Z.; Zhao, X.; Gao, X.; Xie, P. Landscape pattern change and evaluation of ecosystem service value in Lancang County. Ecol. Sci. 2016, 35, 143-153.

43. Qiu, L.; Pan, Y.; Zhu, J.; Amable, G.S.; Xu, B. Integrated analysis of urbanization-triggered land use change trajectory and implications for ecological land management: A case study in Fuyang, China. Sci. Total Environ. 2019, 660, 209-217. [CrossRef] 
44. Raviv, O.; Shamir, S.Z.; Izhaki, I.; Alon, L. The effect of wildfire and land-cover changes on the economic value of ecosystem services in Mount Carmel Biosphere Reserve, Israel. Ecosyst. Serv. 2021, 49, 101291. [CrossRef]

45. Mendoza-González, G.; Martínez, M.L.; Lithgow, D.; Pérez-Maqueo, O.; Simonin, P. Land use change and its effects on the value of ecosystem services along the coast of the Gulf of Mexico. Ecol. Econ. 2012, 82, 23-32. [CrossRef]

46. $\mathrm{Li}, \mathrm{H}$. Research on accelerating the construction of the Greater Zhengzhou Metropolitan Area and promoting the integrated development of the metropolitan area and surrounding cities. Beauty Times Urban Ed. 2017, 11, 1-2.

47. The People's Government of Henan Province. Available online: https://www.henan.gov.cn/2007/03-05/270848.html (accessed on 5 March 2007).

48. The People's Government of Henan Province. Available online: https://www.henan.gov.cn/2007/02-01/245501.html (accessed on 1 February 2007).

49. Yang, J.; Xie, B.; Zhang, D.; Tao, W. Climate and land use change impacts on water yield ecosystem service in the Yellow River Basin, China. Environ. Earth Sci. 2021, 80, 72. [CrossRef]

50. Nita, M.R.; Nastase, I.I.; Badiu D, L.; Gavrilidis, A.A. Evaluating urban forests connectivity in relation to urban functions in romanian cities. Carpathian J. Earth Environ. Sci. 2018, 13, 291-299. [CrossRef]

51. Zhang, Q.; Chen, C.; Wang, J.; Yang, D.; Zhang, Y.; Wang, Z.; Gao, M. The spatial granularity effect, changing landscape patterns, and suitable landscape metrics in the Three Gorges Reservoir Area, 1995-2015. Ecol. Indic. 2020, 114, 15. [CrossRef]

52. Zhang, D.; Wang, W.; Zheng, H.; Ren, Z.; Zhai, C.; Tang, Z.; Shen, G.; He, X. Effects of urbanization intensity on forest structuraltaxonomic attributes, landscape patterns and their associations in Changchun, Northeast China: Implications for urban green infrastructure planning. Ecol. Indic. 2017, 80, 286-296. [CrossRef]

53. Ouyang, W.; Skidmore, A.K.; Hao, F.; Toxopeus, A.G.; Abkar, A. Accumulated effects on landscape pattern by hydroelectric cascade exploitation in the Yellow River basin from 1977 to 2006. Landsc. Urban Plan. 2009, 93, 163-171. [CrossRef]

54. Byomkesh, T.; Nakagoshi, N.; Dewan, A.M. Urbanization and green space dynamics in Greater Dhaka, Bangladesh. Landsc. Ecol. Eng. 2012, 8, 45-58. [CrossRef]

55. Lamine, S.; Petropoulos, G.P.; Singh, S.K.; Szabó, S.; Bachari, N.E.Y.; Srivastava, P.K.; Suman, S. Quantifying land use/land cover spatio-temporal landscape pattern dynamics from Hyperion using SVMs classifier and FRAGSTATS((R)). Geocarto Int. 2018, 33, 862-878. [CrossRef]

56. Zhang, L.; Hou, G.; Li, F. Dynamics of landscape pattern and connectivity of wetlands in western Jilin Province, China. Environ. Dev. Sustain. 2020, 22, 2517-2528. [CrossRef]

57. Plexida, S.G.; Sfougaris, A.I.; Ispikoudis, I.P.; Papanastasis, V.P. Selecting landscape metrics as indicators of spatial heterogeneity-A comparison among Greek landscapes. Int. J. Appl. Earth Obs. Geoinf. 2014, 26, 26-35. [CrossRef]

58. Dong, J.; Dai, W.; Shao, G.; Xu, J. Ecological Network Construction Based on Minimum Cumulative Resistance for the City of Nanjing, China. Isprs Int. J. Geoinf. 2015, 4, 2045-2060. [CrossRef]

59. Chen, L.; Wang, Q. Spatio-temporal evolution and influencing factors of land use in Tibetan region: 1995-2025. Earth Sci. Inform. 2021, 1-12. [CrossRef]

60. Zhang, L.; Wu, J.; Yu, Z.; Shu, J. RETRACTED: A GIS-based gradient analysis of urban landscape pattern of Shanghai metropolitan area, China. Landsc. Urban Plan. 2004, 69, 1-16. [CrossRef] 